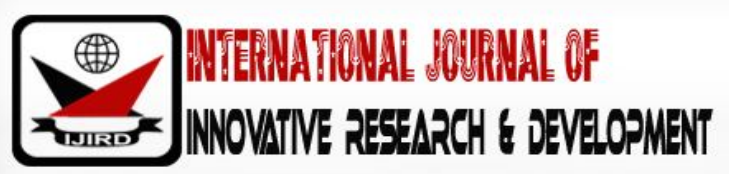

ISSN 2278 - 0211 (Online)

\section{Organizational, Technical and Environmental Influence on Sustainability of Green Energy Projects}

\author{
Simion Kimutai Langat \\ Principal Teacher, Chemalal Secondary School, Kenyatta University, Kenya
}

\begin{abstract}
:
Global warming among many problems arising from climate changes has in advance be a barrier. Green energy is one of the most advocated remedy to the global warming. Despite this advocacy there has been less effort done about it in Africa. Some of the issues includes organizational, technical and environmental factors that affects its sustainability. The paper tries to highly this issues using desk review and find the trend of green energy project in Africa.The findings indicate wide interest in developing sustainable green energy. Donor countries have always been worried with sustainability of green energy. There is a need for technical growth through partnering with private sector and enable technological capacity building. Economic issues acts as an impediment to the sustainability of green energy project. Other arising issues are the political environment of some African countries makes it hard to penetrate with green energy project conflict and wars.Finally it was noted that organization system and structure may affect the sustainability of project positively or negatively. The study concludes that there is need for more research on green energy as well as advancement of green energy to ensure developing countries in Africa countries may access cheap, reliable, sustainable and clean energy.
\end{abstract}

Keywords: Green energy, sustainability of energy, project management, Africa

\section{Introduction}

The world energy scenario has deeply changed in the last few years due to increasing environmental concerns and the attention moving towards the environmental effects caused by the generation of electrical energy. Since time immemorial, the major sources of electricity to power industries, homes, institutions, business premises and other installations has been from non-renewable such as crude oil, coal and natural gas but the challenge has been the adverse environmental effects such as global warming. Green energy comes from specific sources that have the highest environmental benefits since they are nonpolluting and more environmental-friendly. These include solar, wind, geothermal, biogas, eligible biomass and small hydroelectric sources. Renewable include all the green options but also other sources such as large hydroelectric which may have certain environmental tradeoffs. These sources restore themselves over short periods of time and do not diminish.A connection has been sought between energy, development and sustainability (Leva and Zaninelli, 2006).

Green energy is a crucial factor for economic growth, social and industrial development of a country (Asim et al, 2011). Across the planet, different countries use different energy sources to meet consumption demands. However, there has been a shift in emphasis from a carbon emission reduction strategy to a low carbon development called "green development" that aims to achieve a green growth and sustainable development. "Green energy" development has emerged as an alternative energy development strategy and a strategy for climate change mitigation. According to Manoranjan (2012), development of renewable and green energy technologies are the pathways in achieving sustainable energy development and thus a "green" or "smart" economic growth. The prime impetus for accelerating the pace of renewable energy development was provided by the UN conference on new and renewable sources of energy held in the year 1981( Asim et al, 2011). Various issues in harnessing power from the green energy resources involve technology selection, investment, generation, control, government policies, environmental impacts, geographical location, power quality and reliability issues(Lin et al., 2010).

However, the development of renewable energy and green energy sector has been constrained by capital, technology, environment and security issues arising out of internal and external consequences. Pacific Island countries (PICs) are faced with a diversity of energy supply challenges since they rely on imported fuels and renewable energy is expected as the solution. However, the success of this solution is hindered by lack of institutional mechanisms, inadequate policy and regulatory frameworks, and a general lack of human capacity (Anirudh Singh, 2012).To overcome the dependence on imported coal, oil and natural gas fuel, Germany in 1991 passed the Renewable Energy Sources Act (EEG) whose prime aim 
was to facilitate the development of a sustainable energy supply with an aim of increasing the renewable energy share of the power generation mix to at least 12.5 per cent by 2010 and 20 per cent by 2020 (ibid).

Chinese Government attaches great importance to the development of renewable energy and at present, wind, solar, biomass and other relatively mature technologies have already had their preliminary industrial base, and the R\&D of geothermal energy, hydrogen energy, and ocean energy technology has also made some progress (Zhongying, 2009). Amongst the perceived requirements for the development of the renewable energy sector are the availability of indigenous renewable energy resources, the appropriate policy frameworks, facilitating legislations and institutional and human capacity (Anirudh, 2012)

Africa is endowed with vast renewable sources of energy and it is estimated that the continent has 1,750TWh potential of hydropower and 14,000 MW of geothermal potential. The continent receives abundant solar radiation through the year, and recent studies have confirmed the availability of abundant wind energy resources along some of the coastal and specific inland areas of Africa. Africa is among all developing areas of the world, the continent where needs are the most urgent. In Africa, less than 7\% of the hydropower potential has been developed while more that $60 \%$ of its population does not have access to electricity. This highlights the contrasts of a continent well-endowed with energy resources and the deprivations of its population, industries and businesses of the minimum energy services and products that they require to face the challenges of modern lives and economic growth. Given the low energy consumption in most of African countries and the huge needs in capital to develop hydropower energy resources, ensuring the whole energy security is only possible by scaling- up regional power supply and transmission networks (World Energy Council, 2003).

In Eastern African region, this is the main mandate of the Regional Power Pools to facilitate regional energy planning and development of large energy projects on a regional basis (All Africa Energy Week, 2012). In Kenya, the infrastructure development sector is in the spotlight as the Government, companies and consumers grapple with issues such as availability, condition, security of supply, environmental impact and affordability. The sector is on a journey of major change, and holds the key to the country's economic growth as articulated in the Country's Vision 2030.

Kenya's National Energy Policy is designed "to facilitate provision of clean, sustainable, affordable, reliable and secure energy services at least cost while protecting the environment." The efforts come alongside a critical time for Kenya economic growth and energy demand are higher than ever. The current supply, although increasing slowly, cannot keep up with demand. In response, the Kenyan government is using three policy tools to facilitate the adoption of renewable energy. The aim is to increase the country's energy supply, close the demand gap, and ultimately enable economic growth for Kenya. Less than $20 \%$ of the total population estimated at 40 million and $5 \%$ of the rural population in Kenya has access to electricity (World Bank, 2009). The government realizes that oil dependence is unsustainable. Therefore, its long-term development strategy focuses increasing dependence through feed-in tariffs for renewables such as solar, wind, and geothermal. Kenya has several national policy documents, long-term plans, and strategic initiatives designed to promote and invest in green energy for the country, including: Kenya's Scaling Up Renewable Energy Program (SREP) Investment Plan, Least Cost Power Development Plan (LCPDP), Rural Electrification Master Plan, The Energy Act of 2006, The Feed-in Tariff (FiT) Policy, The Kenya National Climate Change Response Strategy and Kenya Vision 2030. The government is making a conscious effort to increase dependence on green energy other than hydroelectric. However, various obstacles exist in developing green energy sources depending on energy source, implementation location, and technology available (Geller, 2003; Mendonça, 2007; McCormick, 2007). Despite the fact that these past studies have focused on generation and implementation of green energy projects little has been shown on sustainability. It is imperative to study how these projects can be sustained. The incorporation of sustainability in project management can be used as a lever to deliver all projects sustainably (Sudha et al, 2016). Sustainable project management is a field of study currently in its infancy but with great potential given the many benefits projects offer as vehicles of change. Developing countries should institute policies that would encourage the launching of renewable electric energy projects(Eugene K \& Umar B., 2015). The sustainability of off grid systems is a problem in most small island states; off grid systems installed under government or donor funded rural electrification programs are not commonly maintained with systems failing as a result (ibid).

Most developed countries have invested heavily in renewable and green energy projects and therefore it is imperative to study how these green energy projects can be sustained beyond post implementation stage.

\section{Literature Review}

The Sustainability theory was found to the best suitable theory. The concept behind sustainability theory is the capacity to maintain some entity, outcome or process overtime (Jenkins, 2004). In general, sustainability refers to the property of being sustainable. This theory is applicable to the operations of green energy projects as their sustainability may improve their survival rate. According to Rosenbaum, (1993), sustainability means using methods, systems and materials that won't deplete resources or harm natural cycles. The long term health of a nation depends on the sustainability of development projects that operate in the country (Amrule, 2013).Within the development community, the notion of sustainability came to be applied to financial resources, including project funds, indicating that projects and donor support are not limitless and must be used efficiently in ways that local actors support so that benefit flows are sustained (USAID, 2005). In this study, since green energy projects implemented need to be sustainable in the long run, to sustain human desire for energy, the effects of 
climatic change and physical environment will be controlled as it will curb adverse effects on the climate and resolve the modern day energy challenges.

\subsection{Sustainability of Green Energy Projects}

Sustainability means ensuring that the benefits realized are maintained and continue after the end of the project. Some of the main factors influencing sustainability include policy, institutions, regulatory environment, social and political issues, project design and implementation (Tango International,2009;Doukas et al., 2010, Tugrul D., 2012). The Obama-Biden comprehensive New Energy for America plan aims to have 10 percent of US electricity coming from renewable sources by 2012, and 25 percent by 2023 (Tugrul D. et al, 2012). To achieve this, the US government offers incentives that help the technologies and funds research and development activities (ibid). In as much as this is an ambitious undertaking, there is little to show efforts to sustain it.

Ecological degradation, climate change and social conditions are among the main sustainability issues pressing the whole biofuel industry at present (Ladanai and Vinterback, 2009). Some leading biofuel-importing countries in the EU have already begun developing their respective national sustainability criteria sets for biomass. The three main issues of sustainability; environmental, social and economic were obviously elicited for the criteria development. Additionally, other criteria such as; practical management, scientific facts and studies, legislations and life cycle thinking were also mentioned as important in the setting sustainability criteria(Anne et al,2011)

The main criteria for green energy source development are: quantitative abundance of resources, acceptable cost of technologies, compatibility with objectives of economic growth, reliability of supply options, political factors, geographical location, environmental and climatic implications (Doukas et al., 2010) . But the identification of the most critical factors like environmental and climatic conditions plays a vital role in selecting Green energy sources. In the ways of utilizing these green resources, a lot of new challenges are faced in planning, criteria evolution, implementation and management (ibid).

In as much as these studies have shown ambitious undertaking, there is little to show efforts towards sustaining it. For instance the US government has come up with ambitious programs in renewable energy, but little effort is seen on sustainability. There is a lot on paper and conferences but modest impact on the ground. Therefore, there is need to investigate this disconnect. Most of the projects in developing countries are donor funded and if issues on sustainability are not addressed then the funds will be lost and the destruction of the environment will continue.

\subsection{Technical Factors and Sustainability}

Technical factors may include human capacity, technology, project design and implementation. According to Tugrul D. et al, the American government needs to make sure there are adequate complimentary technologies to the intermittent renewable sources (solar and wind) to ensure the grid reliability. The government also needs to put more funding into dual renewable plants such as wind or solar combined with pumped hydro, to ensure environmental effects and reliability are both maintained.

The commitment toward greater sustainability in the Gulf Cooperation Countries (GCC) region has translated into the implementation of a number of renewable energy projects over the past few years. The most advanced country in the region in terms of Renewable Energy Sources project implementation is the UAE but Renewable Energy has started gaining momentum in the other GCC countries (Rabia et al, 2013). He suggested that governments should provide incentives for R\&D institutions topromote knowledge and innovation and acquire expertise in the sector of Renewable energy technologies. A properRenewable Energy Technology (RET) policy framework should ensure that private energy investments are movingtowards a diversified RET direction(ibid).

Despite the fact that the GCC states seem to have initiated the implementation of RE projects, the effort to the adoption and development of $\mathrm{RE}$ in the region is hampered by technological barriers, including the insufficient experience, the absence of country assistance in RE market strategies as well as the intermittent nature of RES; power from sources such as solar and wind cannot provide the same level of uninterruptible dispatch as power from conventional fuels ( Rabia et al 2013).

The technology used in the utilization of Renewable Energy in a country is the appropriate one, both from the resources and economic points of views (Anirudh, 2012). Yardsticks to assess the merits of RE technologies must obviously include the avoided cost (i.e. how much savings accrue from replacing other forms of energy with RE). They must also include the capital costs of installation and maintenance costs of the RETs (ibid)

The inherent efficiency of the technology in converting the RE resource to a useful form of energy (usually electricity) is also important

Several $R \& D$ institutions have been set up, various research programmes initiated, and initial steps taken towards the creation of technology clusters focused on RETs to spur innovative processes in the GCC (Rabia et al).

These studies have shown the concern for developing RE technologies but much needs to be done. In my view greater financing should go towards research and development on these technologies rather than attempting to bring down the cost since in the long run it will be beneficial. The private sector should also be brought board in partnership with the governments on collaborative research, capacity building. In most studies, it is only the government institutions that are directly involved because of international agreements but there is need for the private institutions to take a central role. This will ensure that these projects are sustainable. 


\subsection{Economic Factors and Sustainability}

Economic factors may include interest rates, taxation levels, exchange rates, inflation among others. The US government is funding the efforts in wind and solar significantly and they are showing growth, although at the current rates they will fall short of the 2023 goal of 25 percent renewable energy (Tugrul D. et al, 2012). He further suggested that, Federal and regional governments can provide incentives ranging from regulations and standards to financial instruments, or tax incentives as well as grants to those developing or adopting the technologies. For renewable energies to be competitive in the long run considerable research needs to go into driving down the cost so there is not a need for subsidies.

Financial barriers and the high capitals required for the implementation of renewable energy projects are of concern (Shum, 2010). This is because it involves huge capital investment during installation.There is no subsidy mechanism that exists in the Gulf cooperation council states for renewable technologies whose production cost is much higher than that of conventional power (Anirudh S., 2012)

According to Rabia et al (2013), it is of significant importance that the pricing mechanism of conventional fuels should be consolidated in order to take into consideration the environmental impact of excessive fossil fuels' consumption. He further remarked that the Gulf cooperation council nations should support end-use of renewable energy technologies both by promoting advertising campaigns - in order to edify environmental awareness - and by providing incentives for consumers to adopt these technologies for residential, commercial and industrial use.

Once subsidy levels have been established, local policies can be amended to drive investment in those areas where they have the greatest ability to harness resources where those resources are both plentiful and cost effective (Craig Froome, 2010). He also pointed out that government at all levels need to weigh up economic and environmental issues when looking at policy decisions, while one policy may stimulate the economy, the effect that it has on policy aimed at mitigating greenhouse gas emissions and other climate change issues may be significant( ibid)

According to Manoranjon (2012), overdependence on fossil fuels especially on oil on one hand and GHGs, global warming and climate change on the other are critical energy sector challenges.The empirical research has indicated concern for huge cost of implementing the green energy projects and left out on maintaining and sustaining the same projects. In my view, non-renewable should be heavily taxed and renewable should be subsidized and supported by governments should be assured when the donor support stops.

\subsection{Political Factors and Sustainability}

Project sustainability requires political will at all levels of government to commit resources for ongoing development activities. In the context of scarcity of resources and competing demands from increasingly politicized groups, resource allocation is more likely to take place in response to the dictates of political expediency instead of economic rationality. The state of the art of project sustainability should, therefore, reflect the economic and political realities of the country (IEG,ADB, 2010).

Political factors include government policies, change in legislation and breach of contracts among others. Political factors play a great role in the adoption of renewable energy. For example, the creation of renewable portfolio standards (RPS) was one of the major factors in the surge of renewable energy in the US (Daim and Cowan, 2010). enabling government policy and regulatory frameworks will still need to be designed and implemented, in order to create the conditions needed to attract investors and developers for RE to become a significant partof the energy mix. Creation of entities devoted to the development of policies and regulations and follow up on their implementation will be a necessary stepping stone (Rabia F. et al). The major barrier for Saudi Arabia and UAE to hasten the adoption of RE is the absence of a clear legal framework, outbidding RE vast deployment(ibid).

The biggest barrier to the development of a science and technology base for RE seems to be a general lack of awareness of the relevance of these disciplines for such development and this is due to the absence of the appropriate value system, and to lack of vision amongst the politicians (Anirudh, 2012). The scientific intelligentsia, who are the usual group of advisors who help develop standards and proffer scientific advice to the political decision makers in a country is virtually nonexistent in the PICs (Ibid).

Mauritius and Trinidad and Tobago have in place the government institutional frameworks that facilitate and support research and developmental activities in REs.

Most of the PICs lack energy policies especially RE policies. More education and awareness are needed on EC and green energy development. Using CFLs and other appropriate lighting in buildings and converting into green buildings, integrating bio-fuels into business applications, promoting clean and green energy investments and technologies can help achieving a low-carbon and sustainable green energy development(Manoranjan, 2012).Most of the studies have indicated the need for strong institutional and policy frameworks but there is little evidence on government commitment and implementation of the said policies. Issues of sustainability of green energy projects should be integrated in institutional curricula so that awareness is created. A lot of awareness has been created on the dangers of non-renewable while on the other hand little has been done on renewable in terms of promotion. There is also need to establish whether there is political interference and bureaucratic red tape. 


\subsection{Organizational Factors and Sustainability}

Organizational factors may include management systems, organizational structures, HRM and stakeholder involvement. Stakeholders' involvement through meetings and consultations, can strongly articulate common views and opinions about sustainability criteria (Anne et al, 2011).

While one of the necessary conditions for project sustainability is active involvement of beneficiaries in planning and managing development activities, there are numerous constraints on meaningful community participation in some of the developing Asian countries. These include inability of some governments to provide an adequate framework for community participation, weak local leadership, rigidity of project planning and management procedures, and heterogeneity of local communities. Where top down, centralized procedures for community participation are not in place, communities should not be expected to sustain development projects which are based on the naive assumptions of central planners (ADB 2010).

It is certainly a good time to examine the (potential) role of Social Enterprises in the production and utilization of RE since they embrace both social and environmental values, which they are likely to express through a range of good management practices such as recycling, reducing energy use or using green energy where possible( Dan van der Horst, (2008).

Social aspects were considered to be one of the driving factors for renewable energy generation. Major social factor is really emotional reactions to world events. Recent nuclear crisis in Japan for example was major blow to the nuclear industry which the public was warming up to recently due to climate change debate (Paola S., 2010).The empirical studies have emphasized the stakeholder involvement as critical in sustainability. In my view there should be proper stakeholder mapping so as to identify critical stakeholders. The challenge has always been which stakeholder is important, has interest in the project, involved or will be impacted negatively or positively by the project.

There is also a need to investigate the influence of organizational structures and management systems on sustainability of green energy projects.

\section{Objective of the Study}

The general objective of the study is to investigate the influence of the organizational, technical and environmental factors on sustainability of green energy projects.

\section{Research Methodology}

The paper used desk review discussion of various literatures with African. This were then thematically reviewed to understand what green energy sustainability in developing countries.

\section{Findings and Discussion}

The paper finds that though most countries have taken a wide range of initiatives to develop green energy but little has been done on sustainability. Secondly, there is a growing interest in developing renewable and green energy in those countries that have abundant non-renewable sources of energy such as Middle East countries. Thirdly, technical, environmental, social and economic aspects are seen as critical factors for sustainability. Scholars and R\&D teams should come up with affordable renewable energy technologies to harness and develop green energy.Much of the empirical research in various countries has focused on implementation of green energy projects but little on sustainability. More importantly little has been done on sustainability in the Kenyan context. The ones done on Kenyan context has focused on few types of green energy sources such as geothermal and biogas and studies on wind, small hydro's and solar might yield different results. It is for this reason that there was a need to investigate the determinants of sustainability of green energy projects.

\subsection{Sustainability of Green Energy Projects}

In as much as these studies have shown ambitious undertaking, there is little to show efforts towards sustaining it. For instance the US government has come up with ambitious programs in renewable energy, but little effort is seen on sustainability. There is a lot on paper and conferences but modest impact on the ground. Therefore, there is need to investigate this disconnect. Most of the projects in developing countries are donor funded and if issues on sustainability are not addressed then the funds will be lost and the destruction of the environment will continue.

\subsection{Technical Aspects}

Technical factors may include human capacity, technology, project design and implementation.These studies have shown the concern for developing RE technologies but much needs to be done. In my view greater financing should go towards research and development on these technologies rather than attempting to bring down the cost since in the long run it will be beneficial. The private sector should also be brought board in partnership with the governments on collaborative research, capacity building. In most studies, it is only the government institutions that are directly involved because of international agreements but there is need for the private institutions to take a central role. This will ensure that these projects are sustainable. 


\subsection{Economic Issues}

Economic factors may include interest rates, taxation levels, exchange rates, inflation among others. The empirical research has indicated concern for huge cost of implementing the green energy projects and left out on maintaining and sustaining the same projects. In my view, non-renewable should be heavily taxed and renewable should be subsidized and supported by governments should be assured when the donor support stops.

\subsection{Political Aspects}

Political factors include government policies, change in legislation and breach of contracts among others. Most of the studies have indicated the need for strong institutional and policy frameworks but there is little evidence on government commitment and implementation of the said policies. Issues of sustainability of green energy projects should be integrated in institutional curricula so that awareness is created. A lot of awareness has been created on the dangers of non-renewable while on the other hand little has been done on renewable in terms of promotion. There is also need to establish whether there is political interference and bureaucratic red tape.

\subsection{Organizational Issues}

Organizational factors may include management systems, organizational structures, Human Resource Management and stakeholder involvement

The empirical studies have emphasized the stakeholder involvement as critical in sustainability. In my view there should be proper stakeholder mapping so as to identify critical stakeholders. The challenge has always been which stakeholder is important, has interest in the project, involved or will be impacted negatively or positively by the project. There is also a need to investigate the influence of organizational structures and management systems on sustainability of green energy projects.

\section{Conclusion}

Despite the fact that a lot of emphasis has been placed on development of renewable energy projects little research has been done on sustainability of these energy sources and in particular the green energy sources. The research studies undertaken so far have concentrated on developed countries and scanty studies have been done on sustainability of these energy sources in developing countries particularly African countries.

Though green energy development and sustainability is costly in the short run, it has more benefits in the long run and thus countries should embrace it. In the wake of conflicts centering on crude oil energy crisis, the idea of exploring and utilizing green energy is a panacea to peaceful coexistence amongst communities. I agree with most scholars who think green energy is a sustainable source of energy since it is inexhaustible and can be renewed within a short period. Scholars and Research \&Development teams should come up with cheap technologies to harness and develop green energy. The industrial sector (major consumer of energy) should shift towards lighter and cheap technologies that use less energy as opposed to heavy industries that need to be powered by a lot of energy.

\section{References}

i. All Africa Energy Week (2012). Renewable Energy and Electricity Prices in Africa.Economics for Energy, working paper WP01, 2012

ii. Anirudh S. (2012), Renewable energy in the Pacific Island countries: resources, policies and issues, Management of Environmental Quality: An International Journal, Vol. 23 Iss 3 pp. 254 - 263

iii. Anne H. Virgilio P. Mirja M. Lassi L. Jussi H. (2011),Sustainability criteria for biomass - views of Finnish stakeholders, International Journal of Energy Sector Management, Vol. 5 Iss 2 pp. 307 - 326

iv. Asim D. Amitava R. Gautam B. Hiranmay S., (2011),Green energy sources (GES) selection based on multi-criteria decision analysis (MCDA), International Journal of Energy Sector Management, Vol. 5 Iss 2 pp. 271 - 286

v. Business Ethics 108 (3): 285-298 Miles, Samantha (2012). "Stakeholders: essentially contested or just confused?". Journal of Business Ethics 108 (3): 285-298.

vi. Commission of the European Communities (2007). Did the financial crisis lead to changes in private equity investor preferences regarding renewable energy and climate policies? Energy Policy, 47,111-116.

vii. Craig Froome, (2010), Renewable energy in Australia: 20 per cent by 2020, Management of Environmental Quality: An International Journal, Vol. 21 Iss 2 pp. 177 - 186

viii. Geller, H. (2003). Energy Revolution, Polices for a Sustainable Future. Island Press

ix. Hemami, A. (2012). Wind turbine technology. Clifton Park, NY: Delmar, Cengage Learning.

x. Kelly, G. (2007), Renewable energy strategies in England, Australia and New Zealand. Science, 37, 326-338.

xi. Leva E. and Zaninelli, P. (2006). Occurrence of negative prices on the German spot market for electricity and their influence on balancing power markets. Proceeding paper EEM2010 - 7th international conference on the European energy market.

xii. Miles, S. (2012). "Stakeholders: essentially contested or just confused?". Journal of 
xiii. Mugenda, O. M., \& Mugenda, A. G. (2003). Research Methods: Quantitative \&Qualitative Approaches. Nairobi: Acts Press.

xiv. Manoranjan M., (2012), New renewable energy sources, green energy development and climate change, Management of Environmental Quality: An International Journal, Vol. 23 Iss 3 pp. 264 - 27441

xv. Obama, B. and Biden, J. (2009), New energy for America, available at: http:/ / my.barackobama.com/ page/ content/ newenergy

xvi. Paola S. Gabriella M., (2004), Exploitation of renewable energy sources and sustainable management of the territory, Management of Environmental Quality: An International Journal, Vol. 15 Iss 1pp. 41 - 47

xvii. Rabia F, Noor G. Stella A. Diala H. Toufic M., (2013), Renewable energy in the GCC: status and challenges", International Journal of Energy Sector Management, Vol. 7 Iss1 pp. 84 - 112

xviii. Salim, F. (2012). Facility Siting and Public Opposition New York: Van Nostrand

xix. Saunders, Lewis and Thornhill: Research Methods for Business Students, Third edition, Additional Case Studies ( Pearson Education Limited 200331

xx. Solanki, C. (2011). Solar photovoltaics: Fundamentals, technologies and applications.

xxi. Tugrul D., Georgina H. Liliya H., (2012), Forecasting renewable energy production in the US, Foresight, Vol. 14 Iss 3 pp. 225

xxii. World Energy Council Renewable Energy Projects Handbook, 2003

xxiii. Zervos, J. (2007), "Infrastructure and Poverty in Vietnam." LSMS Working Paper No. 121. The World Bank. Washington, D.C.

xxiv. Zhongying Wang Junfeng Li, (2009), China's renewable energy development, International Journal of Energy Sector Management, Vol. 3 Iss 1 pp. 50 - 61 